\title{
U-Pt-Sm-Ba-O Chemical Pinning Centers in Ag-Doped Sm123 Textured in Reduced Oxygen
}

\author{
Ravi-Persad Sawh, Roy Weinstein, Drew Parks, Noriko Chikumoto, and Masato Murakami
}

\begin{abstract}
In the $\mathrm{U} / \mathrm{n}$ process enriched uranium is admixed to HTS powders, textured and then irradiated with thermal neutrons. Neutrons must penetrate several centimeters for such processing to be successful in textured materials. Bulk $\mathrm{Sm} 123$ cannot be $U / n$ processed because thermal neutrons penetrate $<1 \mathrm{~mm}$. However, textured $\mathrm{Sm123}$ can still benefit from chemical pinning centers that are formed during U/n processing. Thin or thick films of Sm123 can still be successfully $U / n$ processed. In the present work, powders containing $\mathrm{Ag}_{2} \mathrm{O}+20 \mathrm{~mol} \% \mathrm{Sm} 211+\mathrm{Sm} 123+\mathrm{Pt}$ are doped with depleted $U$, and textured in a $1 \%$ oxygen atmosphere. Microstructure studies indicate the presence of small deposits of $\left(\mathrm{U}_{0.5} \mathbf{P t}_{0.5}\right) \mathrm{SmBa}_{2} \mathrm{O}_{6}$, which are double perovskites. Important characteristics of the $\mathrm{U}-\mathrm{Pt}-\mathrm{Sm}-\mathrm{Ba}-\mathrm{O}$ particles are: (a) average size is $500 \mathrm{~nm}$, (b) distribution is fairly uniform within the Sm123, (c) the number of deposits is proportional to the mass of admixed $U$ (i.e., size is constant for increasing doping levels) (d) $U$ does not substitute into the background $\mathrm{Sm123}$, (e) Ag does not interact with either $\mathrm{U}$ or $\mathrm{Pt}$, and (f) there is less coarsening of the $\mathrm{U}$-rich particles when the dwell time of the maximum temperature in the temperature versus time profile is $<2$ hours. The $\mathrm{U}-\mathrm{Pt}-\mathrm{Sm}-\mathrm{Ba}-\mathrm{O}$ deposits are strikingly similar to the $\mathrm{U}-\mathrm{Pt}-\mathrm{Y}-\mathrm{Ba}-\mathrm{O}$ deposits found earlier in U-doped Y123. Tungsten or molybdenum can be used as nonradioactive substitutes for uranium to produce similar double perovskites deposits.
\end{abstract}

Index Terms-Critical current density, high-temperature superconductors, melt-textured Sm123, pinning centers.

\section{BACKGROUND}

$\mathbf{E}$ VER since the discovery of high temperature superconductors (HTS) there has been an ongoing worldwide research effort to bring this material to the marketplace. With recent developments in the processing of bulk HTS these materials are excellent candidates for use as, for example, trapped field magnets (TFM's). Textured HTS can now sustain trapped magnetic flux density of up to $16 \mathrm{~T}$ [1].

Trapped magnetic flux density of HTS can be further increased, without the need to improve alignment of microcrystal axes or to clean crystal interfaces, by the introduction of

Manuscript received August 5, 2002. This work was supported in part by the U.S. Army Research Office, the Welch Foundation, and the State of Texas via the Texas Center for Superconductivity and Advanced Materials (TCSAM). The New Energy and Industrial Technology Development Organization (NEDO) of Japan also supports this work as a Collaborative Research and Development of Fundamental Technologies for Superconductivity Applications.

R.-P. Sawh, R. Weinstein, and D. Parks are with the Department of Physics and Texas Center for Superconductivity and Advanced Materials, University of Houston, Houston, TX 77204-5005 USA (e-mail: rsawh@uh.edu).

N. Chikumoto and M. Murakami are with the Superconductivity Research Laboratory, International Superconductivity Technology Center, Tokyo 105-0023, Japan.

Digital Object Identifier 10.1109/TASC.2003.812127 additional pinning centers. A Pinning center is a nonsuperconducting or poorly superconducting region in the HTS that can trap a quantum of magnetic flux. Pinning centers in HTS increase its critical current density $\left(J_{c}\right)$ and hence trapped magnetic flux density. Pinning centers in textured HTS can be created by chemical, mechanical, or irradiation techniques. One such technique that includes both chemical and irradiation methods is $\mathrm{U} / \mathrm{n}$ processing [2].

In the $U / n$ process enriched uranium $\left({ }^{235} \mathrm{U}\right)$ is admixed to HTS powders, textured and then irradiated with thermal neutrons. During texturing, $\mathrm{U}$ interacts with other elements, e.g., $\mathrm{Y}$ and $\mathrm{Ba}$ in $\mathrm{YBa}_{2} \mathrm{Cu}_{3} \mathrm{O}_{x}$ (Y123) and $\mathrm{Pt}$ in Pt-doped $\mathrm{Y} 123$, to form deposits of $\left(\mathrm{U}_{0.6} \mathrm{Pt}_{0.4}\right) \mathrm{YBa}_{2} \mathrm{O}_{6}$ (U-Pt-Y-Ba-O). These deposits average $300 \mathrm{~nm}$ in diameter and increase in number (i.e., their average diameter is constant) for increasing mass of admixed $\mathrm{U}$. The structure of the U-Pt-Y-Ba-O deposit was identified by $\mathrm{x}$-ray diffraction (XRD) to be a double perovskite. Prior to irradiation, the $\mathrm{U}-\mathrm{Pt}-\mathrm{Y}-\mathrm{Ba}-\mathrm{O}$ deposits act as pinning centers to increase $J_{c}$ and hence trapped magnetic flux density. Increases in $J_{c}$ of up to $150 \%$ have been reported in U-doped Y123 [3]. After irradiation with thermal neutrons additional pinning centers are created. This resulted in a further increase in $J_{c}$ by factors of 11-40 [4]. Trapped magnetic flux density of up to $2.1 \mathrm{~T}$ in single disks, with a diameter of $2 \mathrm{~cm} \times 0.8 \mathrm{~cm}$ thick, have been measured in U/n processed Y123 [4]. The effect of the chemical pinning centers created during texturing and the irradiation pinning centers created by thermal neutron irradiation are multiplicative (i.e., they increase $J_{c}$ independently of each other).

Conditions for successful U/n processing of textured HTS include, among other variables, the requirement that thermal neutrons penetrate several centimeters of the HTS. Bulk $\mathrm{SmBa}_{2} \mathrm{Cu}_{3} \mathrm{O}_{x}$ (Sm123) cannot be $\mathrm{U} / \mathrm{n}$ processed because thermal neutrons will only penetrate $<1 \mathrm{~mm}$ [5]. Since the U/n process creates several different independent types of pinning centers, textured Sm123 can still benefit from the U-rich deposits that are formed during texturing. These chemical deposits should act as pinning centers to increase $J_{c}$ in Sm123. Although bulk Sm123 cannot be completely U/n processed, thin or thick films or any other processing technique where the final thickness of the $\mathrm{Sm} 123<1 \mathrm{~mm}$ can still be effectively processed by this technique.

Early experiments on U-doped Sm123 [5], [6] have demonstrated the creation of small U-rich deposits. For example, when $\mathrm{U}$ is admixed to Ag-free powders containing $20 \mathrm{~mol} \%$ $\mathrm{Sm} 211+\mathrm{Sm} 123+0.5 \mathrm{wt} . \% \mathrm{Pt}$ and textured in a $1 \%$ oxygen atmosphere, submicrometer-sized deposits of a U-rich compound were formed. Scanning electron microprobe (SEM) 
showed that these deposits were almost spherical and had an average diameter of $\sim 500 \mathrm{~nm}$. The wavelength dispersive $\mathrm{x}$-ray spectrometer (WDS) and energy dispersive $\mathrm{x}$-ray spectrometer (EDS) facilities of the SEM identified the U-rich compound as $\left(\mathrm{U}_{0.5} \mathrm{Pt}_{0.5}\right) \mathrm{SmBa}_{2} \mathrm{O}_{2}$ (U-Pt-Sm-Ba-O), which is double perovskite in structure. Thus far, every indication is that the $\mathrm{U}-\mathrm{Pt}-\mathrm{Sm}-\mathrm{Ba}-\mathrm{O}$ deposits are strikingly similar to the U-Pt-Y-Ba-O deposits found earlier in U-doped Y123 [3]. The only difference, as we expected, is that the U-rich compound found in Y123 is Y-based whereas in Sm123 it is Sm-based.

Recent results on microstructure studies of $\mathrm{Ag}$ admixed Sm123 doped with $\mathrm{U}$ and $\mathrm{Pt}$ are the subject of this report. Specifically, we report on the effect of increasing the mass of admixed $U$, and on the effect of varying the dwell time of the maximum temperature in the temperature versus time profile.

\section{EXPERIMENTAL PROCEDURE}

HTS powders containing $20 \mathrm{~mol} \% \mathrm{Sm} 211+\mathrm{Sm} 123+$ 0.5 wt. $\% \mathrm{Pt}+10$ wt. $\% \mathrm{Ag}_{2} \mathrm{O}$ was doped with uranium. $\mathrm{U}$ in the form of uranium peroxide $\left(\mathrm{UO}_{4} \bullet 2 \mathrm{H}_{2} \mathrm{O}\right)$, first synthesized circa 1877 [7], was used in these experiments. Powders were then pressed into pellets and textured in a $1 \%$ oxygen $+99 \%$ argon atmosphere. The low oxygen processing technique [8] has made it possible for $\mathrm{Sm} 123$ to be textured with a critical temperature $\left(T_{c}\right)$ comparable to or greater than that of Y123. A trapped magnetic flux density of several Tesla has been reported in bulk Sm123 processed by this method [9].

To investigate the effect of increasing mass of admixed $U$, $\mathrm{UO}_{4} \bullet 2 \mathrm{H}_{2} \mathrm{O}$ was added to the above powders with masses covering the range $0.0 \mathrm{wt} . \%$ to $0.6 \mathrm{wt} . \%$. The samples without $\mathrm{U}$ were used as a control in these experiments. The dwell time $\left(t_{\text {melt }}\right)$ of the maximum temperature in the temperature versus time profile was kept constant. To investigate the effect of $t_{\text {melt }}$ on the U-rich particles, $t_{\text {melt }}$ was varied from 0.2 hours to 4 hours with a $\mathrm{U}$ content fixed at $0.6 \mathrm{wt} . \%$.

Microstructure imaging was done with a JEOL JXA-8600 electron microprobe (SEM). Elemental analysis was done with the wavelength dispersive $\mathrm{x}$-ray spectrometer (WDS) and the energy dispersive $x$-ray spectrometer (EDS) attachments of the SEM. Tests of $J_{c}$ via measurements of trapped magnetic flux density and via vibrating sample magnetometry (VSM) are in progress and will be reported elsewhere.

\section{RESUlTS AND DisCUSSION}

In studies of varying mass of admixed $\mathrm{U} t_{\text {melt }}$ was held constant at 2 hours. Microstructure imaging of textured Ag-Sm123 show small deposits of a U-rich phase (see Fig. 1). When analyzed by WDS and EDS these deposits were found to have the chemical composition $\left(\mathrm{U}_{0.5} \mathrm{Pt}_{0.5}\right) \mathrm{SmBa}_{2} \mathrm{O}_{6}$ (U-Pt-Sm-Ba-O). These deposits have the same chemical composition found in Ag-free U-doped Sm123. Within the limits of the WDS attachment of the SEM, the U-Pt-Sm-Ba-O deposits do not contain $\mathrm{Cu}$. U-Pt-Sm-Ba-O deposits have an almost spherical morphology. They vary in diameter from $\sim 300 \mathrm{~nm}$ to $\sim 1500 \mathrm{~nm}$ with an average of $\sim 500 \mathrm{~nm}$. Their

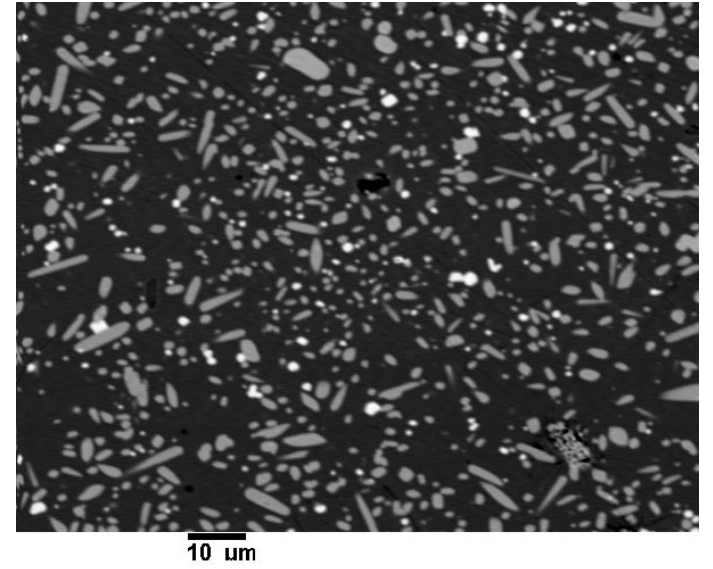

Fig. 1. Microprobe image showing deposits of $\left(\left(\mathrm{U}_{0.5} \mathrm{Pt}_{0.5}\right) \mathrm{SmBa}_{2} \mathrm{O}_{6}\right.$ (small white spots) in textured Sm123. Sm211 particles are the gray spots. Sample composition is $20 \mathrm{~mol} \% \mathrm{Sm} 211+\mathrm{Sm} 123+10$ wt. $\% \mathrm{Ag}_{2} \mathrm{O}+\mathrm{Ag}_{2} \mathrm{O}+$ 0.5 wt. $\% \mathrm{Pt}+0.6$ wt.\% $\mathrm{UO}_{4} \bullet 2 \mathrm{H}_{2} \mathrm{O}$. Dwell time of the maximum temperature in the temperature versus time profile is 2 hours.

observed diameter appears not to vary with the mass of admixed U. Instead, increasing the mass of admixed U resulted in an increase in the number of deposits. The structure of $\mathrm{U}-\mathrm{Pt}-\mathrm{Sm}-\mathrm{Ba}-\mathrm{O}$ deposits is that of a double perovskite. WDS and EDS analyses of the background Sm123 indicated that there was no U present inside the Sm123 crystal matrix.

The presence of a small amount of silver was detected by WDS in the background Sm123 matrix. Since Ag is substituted into the background $\mathrm{Sm} 123$, a small change in $T_{c}$ should be expected. However, since U does not substitute into the Sm123 matrix no additional change in $T_{c}$ should be observed. Although a small amount of Ag enters the Sm123 matrix, the majority of the Ag forms irregular shaped deposits tens of micrometers in size. WDS analysis of the Ag-rich deposits indicates that the composition is primarily an $\mathrm{Ag}-\mathrm{O}$ compound. This observation, together with the observation that the U-rich compound does not contain $\mathrm{Ag}$, suggests that there is no interaction between $\mathrm{U}$ and $\mathrm{Ag}$ and between $\mathrm{Pt}$ and $\mathrm{Ag}$. Earlier experiments on U-doped Sm123 without Ag addition also showed that U-Pt-Sm-Ba-O deposits are formed during texturing. Essentially the identical U-rich deposits are formed in U-doped Ag-Sm123. This inspection indicates that $\mathrm{Ag}$ does not play a role in the creation of $\mathrm{U}-\mathrm{Pt}-\mathrm{Sm}-\mathrm{Ba}-\mathrm{O}$ double perovskite deposits.

Low magnification SEM images of U-doped $\mathrm{Ag}-\mathrm{Sm} 123$ indicate the presence of regions of Sm123 that are completely devoid of the $\mathrm{Sm}_{2} \mathrm{BaCuO}_{y}$ ( $\left.\mathrm{Sm} 211\right)$ secondary particles. The Sm211 segregated areas are irregularly shaped and are up to hundreds of micrometers in size. A closer examination of the $\mathrm{Sm} 211$ free regions shows that they contain the same $\mathrm{Ag}-\mathrm{O}$ compound seen in the areas containing Sm211. The Sm211-free regions are observed in both U-doped and U-undoped samples, as well as in Ag-added and Ag-free samples. More importantly, the Sm211-free areas contain profuse deposits of the U-Pt-Sm-Ba-O double perovskite. In the Sm211-free areas, the size and morphology of the $\mathrm{U}-\mathrm{Pt}-\mathrm{Sm}-\mathrm{Ba}-\mathrm{O}$ deposits are the same as those found in the Sm211-containing Sm123 regions (i.e., spherical in shape with an average diameter of $\sim 500 \mathrm{~nm}$ ). Given that $\mathrm{Sm} 211$-free areas 


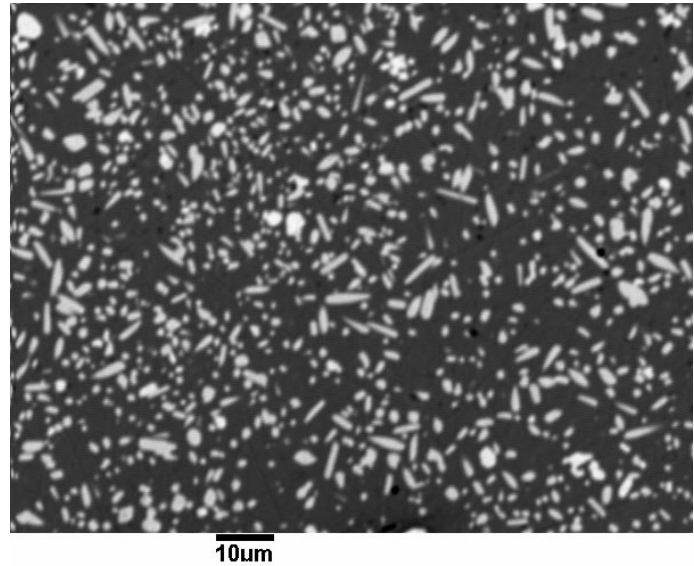

Fig. 2. Microprobe image of textured U-undoped Sm123 showing Sm211 particles (white spots). Sample composition is 20 mol\% $\mathrm{Sm} 211+\mathrm{Sm} 123+10$ wt. $\% \mathrm{Ag}_{2} \mathrm{O}+0.5$ wt. $\%$ Pt (no U admixed). Dwell time of the maximum temperature in the temperature versus time profile is 2 hours.

are seen in both U-doped and U-undoped, and in Ag-added and Ag-free samples, doping U into Sm123 provides a method of introducing chemical deposits that may act as pinning centers in the Sm211-free areas. This may be an added advantage of U-doping into Sm123.

In the normal Sm123 areas (i.e., those containing Sm211), the $\mathrm{Sm} 211$ varies in size from $\sim 500 \mathrm{~nm}$ to several micrometers. For Sm 211 particles that are submicrometer in size their shape tended to be more spherical (see Fig. 2). The micrometer sized Sm211 particles were more elongated in shape (see Fig. 2). No additional refining of the Sm211 particles was observed in U-doped samples when compared to U-undoped samples. The elongation of the $\mathrm{Sm} 211$ particles indicates that $\mathrm{Pt}$, and not $\mathrm{U}$ or $\mathrm{Ag}$, acts as a refining agent to modify their size and shape.

The investigation of dwell time $\left(t_{\text {melt }}\right)$ of the maximum temperature in the temperature versus time profile yielded additional information on the growth pattern of U-Pt-Sm-Ba-O deposits. For $t_{\text {melt }}<2$ hours, the number of deposits was generally constant and was twice that of those samples with higher $t_{\text {melt }}$. The size of the U-Pt-Sm-Ba-O deposits in samples with $t_{\text {melt }}<2$ hours averaged $\sim 500 \mathrm{~nm}$ in diameter (see Fig. 3). For $t_{\text {melt }}>2$ hours, the U-rich deposits tended to coarsen and grew to micrometers sized spheres. It also appears that for longer $t_{\text {melt }}$ (i.e., $t_{\text {melt }}>2$ hours) the U-Pt-Sm-Ba-O deposits agglomerated in addition to coarsening (see Fig. 3). A transition point appears at $t_{\text {melt }}=2$ hours. In some samples the number of $\mathrm{U}-\mathrm{Pt}-\mathrm{Sm}-\mathrm{Ba}-\mathrm{O}$ deposits is equal to that of those with $t_{\text {melt }}<2$ hours, whereas in other samples where $t_{\text {melt }}=2$ hours the number of U-rich particles is equal in number to that of the $t_{\text {melt }}>2$ hours samples. A summary of the number of $\mathrm{U}-\mathrm{Pt}-\mathrm{Sm}-\mathrm{Ba}-\mathrm{O}$ particles, in an area of 2880 square micrometers, for varying $t_{\text {melt }}$ is described in Fig. 4.

In all of the above $\mathrm{U}$ doping experiments depleted $\mathrm{U}$ (i.e., ${ }^{238} \mathrm{U}$ ) was used. Depleted U is mildly radioactive when used in the quantities required for doping into Sm123. Although it is an essentially benign element, the use of depleted $U$ is restricted in some countries. Nonradioactive elements are desired. For example, tungsten and molybdenum can be suitable replacements
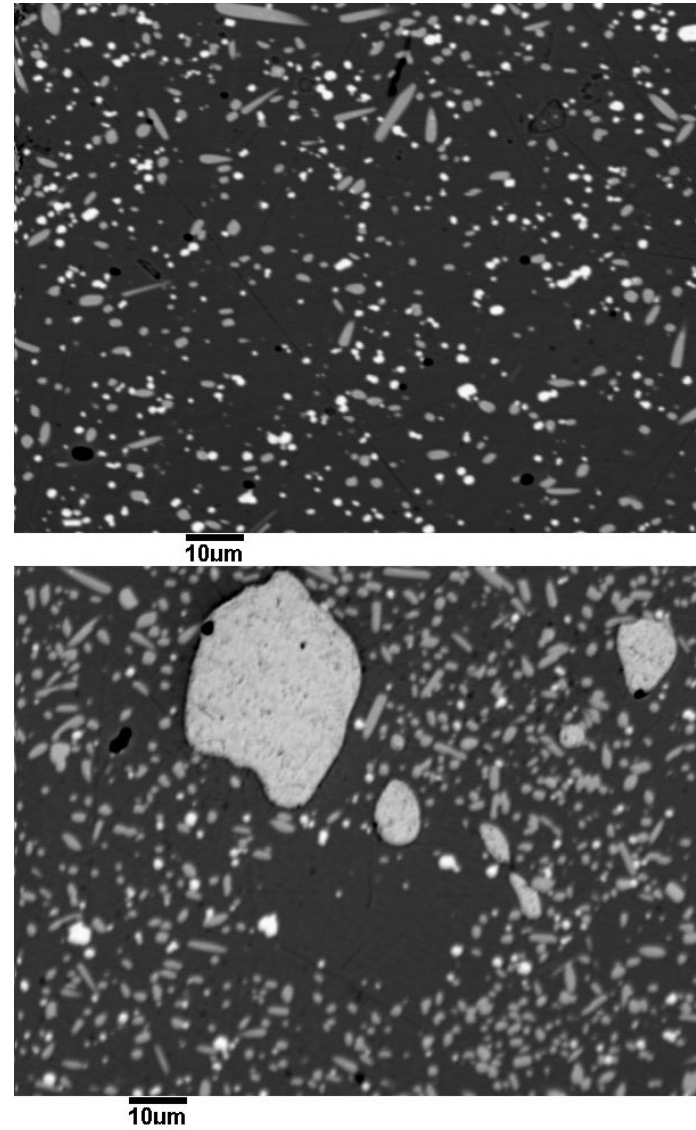

Fig. 3. Microstructure studies showing the effect of dwell time $\left(t_{\text {melt }}\right)$ of the maximum temperature in the temperature versus time profile. Top: $t_{\text {melt }}=$ 0.12 hours (less coarsening of the $\mathrm{U}-\mathrm{Pt}-\mathrm{Sm}-\mathrm{Ba}-\mathrm{O}$ particles is seen). Bottom: $t_{\text {melt }}=4$ hours (coarsening and agglomeration of $\mathrm{U}-\mathrm{Pt}-\mathrm{Sm}-\mathrm{Ba}-\mathrm{O}$ deposits is observed). Sample composition, in both cases, is $20 \mathrm{~mol} \% \mathrm{Sm} 211+\mathrm{Sm} 123+$ 10 wt. $\% \mathrm{Ag}_{2} \mathrm{O}+0.5$ wt. $\%+0.6$ wt. $\% \mathrm{UO}_{4} \bullet 2 \mathrm{H}_{2} \mathrm{O}$.

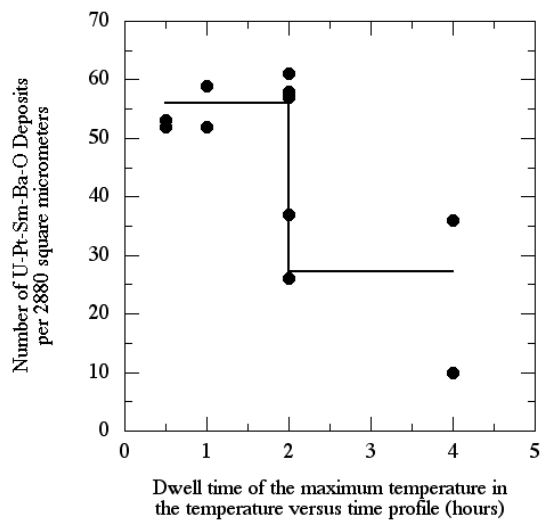

Fig. 4. Variation in the number of $\left(\mathrm{U}_{0.5} \mathrm{Pt}_{0.5}\right) \mathrm{SmBa}_{2} \mathrm{O}_{6}$ deposits as a function of dwell time of the highest temperature in the temperature versus time profile. The line is drawn to guide the eye.

for U [10]. Early work on W-doped or Mo-doped Y123 showed that the same type of double perovskite deposits was formed as in U-doped Y123 [11].

When W and Pt are doped into Y123 powders and textured, profuse W-rich spherical deposits, 200-300 $\mathrm{nm}$ in diameter, were formed. WDS and EDS identified these W-rich deposits as $\left(\mathrm{W}_{0.5} \mathrm{Pt}_{0.5}\right) \mathrm{YBa}_{2} \mathrm{O}_{6}$, a double perovskite. The size of 
the $\mathrm{W}$-rich deposits is independent of the $\mathrm{W}$ doping level. There is no substitution of $\mathrm{W}$ into the Y123 matrix. An increase in $J_{c}$ of up to $60 \%$ was measured. Similar studies of molybdenum doped Y123 indicate deposits 200-300 nm, of $\left(\mathrm{Mo}_{0.5} \mathrm{Pt}_{0.5}\right) \mathrm{YBa}_{2} \mathrm{O}_{6}$, also a double perovskite. The $\left(\mathrm{W}_{0.5} \mathrm{Pt}_{0.5}\right) \mathrm{YBa}_{2} \mathrm{O}_{6}$ and the $\left(\mathrm{Mo}_{0.5} \mathrm{Pt}_{0.5}\right) \mathrm{YBa}_{2} \mathrm{O}_{6}$ are remarkably similar to the $\left(\mathrm{U}_{0.6} \mathrm{Pt}_{0.4}\right) \mathrm{YBa}_{2} \mathrm{O}_{6}$ deposits found in U-doped Y123.

In U-doped $\mathrm{Sm} 123$, with or without $\mathrm{Ag}$ addition, deposits of $\left(\mathrm{U}_{0.5} \mathrm{Pt}_{0.5}\right) \mathrm{SmBa}_{2} \mathrm{O}_{6}$ are formed. These deposits are identical to the $\left(\mathrm{U}_{0.6} \mathrm{Pt}_{0.4}\right) \mathrm{YBa}_{2} \mathrm{O}_{6}$ deposits previously found in U-doped Y123 with the only difference being that $\mathrm{Sm}$ replaces $\mathrm{Y}$ in the Sm123 system. Since W and Mo forms similar double perovskite deposits in Y123, it is very likely that $\mathrm{W}$-doped Sm123 should form a similar double perovskite, i.e., $\left(\mathrm{W}_{0.5} \mathrm{Pt}_{0.5}\right) \mathrm{SmBa}_{2} \mathrm{O}_{6}$. Mo-doped $\mathrm{Sm} 123$ should form equivalent $\mathrm{Sm}$-based deposits, i.e., $\left(\mathrm{Mo}_{0.5} \mathrm{Pt}_{0.5}\right) \mathrm{SmBa}_{2} \mathrm{O}_{6}$. These W-rich and Mo-rich Sm-based double perovskites should also act as pinning centers and increase $J_{c}$ in textured Sm123.

\section{SUMMARY}

This study of U-doped Sm123, textured in reduced oxygen, indicates that profuse small $\sim 500 \mathrm{~nm}$ average diameter) deposits are formed either with or without $\mathrm{Ag}$ addition. The deposits are $\left(\mathrm{U}_{0.5} \mathrm{Pt}_{0.5}\right) \mathrm{SmBa}_{2} \mathrm{O}_{6}$, and are similar to the $\left(\mathrm{U}_{0.6} \mathrm{Pt}_{0.4}\right) \mathrm{YBa}_{2} \mathrm{O}_{6}$ found earlier in U-doped $\mathrm{Y} 123$. Both the Y-based and Sm-based U-rich deposits are double perovskites. The U-Pt-Sm-Ba-O deposits coarsen and agglomerate when the dwell time of the highest temperature in the temperature versus time profile increases. Optimum dwell time appears to be $<2$ hours. Y123 doped with the nonradioactive elements $\mathrm{W}$ or Mo produced similar double perovskite deposits. It is expected that either $\mathrm{W}$ or Mo would form essentially the same type of double perovskites in Sm123 as those found in Y123 except that Y is replaced with Sm in the Sm123 system.

\section{ACKNOWLEDGMENT}

The authors wish to thank the staff of TCSAM's Materials Characterization Facility for technical support and assistance in the electron microprobe studies.

\section{REFERENCES}

[1] S. Gruss, G. Fuchs, G. Krabbes, P. Verges, G. Stöver, K.-H. Müller, J. Fink, and L. Schultz, "Superconducting bulk magnets: Very high trapped fields and cracking," Appl. Phys. Lett., vol. 79, no. 19, pp. 3131-3133, November 2001.

[2] R. Weinstein, "Method of Forming Textured High-Temperature Superconductors," U.S. Patent 6083 885, 4, 2000.

[3] R.-P. Sawh, Y. Ren, R. Weinstein, W. Hennig, and T. Nemoto, "Uranium chemistry and pinning centers in high temperature superconductor," Physica C, vol. 305, no. 3-4, pp. 159-166, September 1998.

[4] R. Weinstein, R. Sawh, Y. Ren, and D. Parks, "The role of uranium, with and without irradiation, in the achievement of $J_{c} \approx 300000 \mathrm{~A} \mathrm{~cm}^{-2}$ at $77 \mathrm{~K}$ in large grain melt-textured Y123," Mater. Sci. Eng. B, vol. 53, no. 1-2, pp. 38-44, May 1998.

[5] R. Weinstein, Y. Ren, R. Sawh, A. Gandini, W. Hennig, M. Murakami, T. Mochida, N. Chikumoto, N. Sakai, G. Krabbes, W. Bieger, D. Milliken, S. X. Dou, S. Tönies, M. Eisterer, and H. W. Weber, "Properties of HTS for successful U/n processing," Physica C, pt. 3, vol. 341-348, pp. 1415-1418, November 2000.

[6] R. Weinstein and R.-P. Sawh, "A class of chemical pinning centers including two elements foreign to HTS," Physica C, to be published.

[7] T. Fairley, "Study of hydrogen dioxide and of certain peroxides," $J$. Chem. Soc., vol. 31, pp. 125-143, 1877.

[8] M. Murakami, S. I. Yoo, T. Higuchi, N. Sakai, J. Weltz, N. Koshizuka, and S. Tanaka, "Flux pinning in melt-grown $\mathrm{NdBa}_{2} \mathrm{Cu}_{3} \mathrm{O}_{y}$ and $\mathrm{SmBa}_{2} \mathrm{Cu}_{3} \mathrm{O}_{y}$ superconductors," Jpn. J. Appl. Phys., pt. 2, vol. 33, no. 5B, pp. L715-L717, May 1994.

[9] H. Ikuta, H. Ishihara, Y. Yanagi, Y. Itoh, and U. Mizutani, "Extracting the utmost from the high performance of $\mathrm{Sm}-\mathrm{Ba}-\mathrm{Cu}-\mathrm{O}$ bulk superconductors by pulse field magnetization," Supercond. Sci. Technol., vol. 15, no. 4, pp. 606-612, April 2002.

[10] M. Benedict, T. H. Pigford, and H. W. Levi, Nuclear Chemical Engineering, 2nd ed. New York: McGraw-Hill, 1981.

[11] R.-P. Sawh, R. Weinstein, D. Parks, A. Gandini, Y. Ren, and I. Rusakova, "Tungsten and molybdenum double perovskites as pinning centers in melt-textured Y123," Physica C, to be published. 